\title{
Practice guideline summary: Use of fMRI in the presurgical evaluation of patients with epilepsy
}

Report of the Guideline Development, Dissemination, and Implementation Subcommittee of the American Academy of Neurology

Jerzy P. Szaflarski, MD, $\mathrm{PhD}$

David Gloss, MD, MPH\&TM Jeffrey R. Binder, MD William D. Gaillard, MD Alexandra J. Golby, MD Scott K. Holland, PhD Jeffrey Ojemann, MD David C. Spencer, MD Sara J. Swanson, PhD Jacqueline A. French, MD William $\mathrm{H}$. Theodore, MD

Correspondence to American Academy of Neurology: guidelines@aan.com

Supplemental data at Neurology.org

\section{ABSTRACT}

Objective: To assess the diagnostic accuracy and prognostic value of functional MRI (fMRI) in determining lateralization and predicting postsurgical language and memory outcomes.

Methods: An 11-member panel evaluated and rated available evidence according to the 2004 American Academy of Neurology process. At least 2 panelists reviewed the full text of 172 articles and selected 37 for data extraction. Case reports, reports with $<15$ cases, metaanalyses, and editorials were excluded.

Results and recommendations: The use of $\mathrm{FMRI}$ may be considered an option for lateralizing language functions in place of intracarotid amobarbital procedure (IAP) in patients with medial temporal lobe epilepsy (MTLE; Level C), temporal epilepsy in general (Level C), or extratemporal epilepsy (Level C). For patients with temporal neocortical epilepsy or temporal tumors, the evidence is insufficient (Level U). fMRI may be considered to predict postsurgical language deficits after anterior temporal lobe resection (Level C). The use of fMRI may be considered for lateralizing memory functions in place of IAP in patients with MTLE (Level C) but is of unclear utility in other epilepsy types (Level U). fMRI of verbal memory or language encoding should be considered for predicting verbal memory outcome (Level B). fMRI using nonverbal memory encoding may be considered for predicting visuospatial memory outcomes (Level C). Presurgical fMRI could be an adequate alternative to IAP memory testing for predicting verbal memory outcome (Level C). Clinicians should carefully advise patients of the risks and benefits of fMRI vs IAP during discussions concerning choice of specific modality in each case. Neurology ${ }^{\circledR}$ 2017;88:395-402

\section{GLOSSARY}

AAN = American Academy of Neurology; ATL = anterior temporal lobe; fMRI = functional MRI; IAP = intracarotid amobarbital procedure; $\mathbf{L I}=$ laterality index; $\mathbf{M T L}=$ medial temporal lobe; $\mathbf{M T L E}=$ medial temporal lobe epilepsy; $\mathbf{R O I}=$ region of interest; TLE = temporal lobe epilepsy.

This article summarizes an American Academy of Neurology (AAN) guideline on use of functional MRI (fMRI) for presurgical mapping in epilepsy. Additional information is provided in the complete guideline, available as a data supplement at Neurology.org. Appendices e-1 through e-5, available in the complete guideline, tables e-1 and e-2, and references e1-e16, cited here, are available at Neurology.org.

The choice of performing intracarotid amobarbital procedure (IAP) or AMRI for presurgical language and memory assessment depends on multiple factors that need to be taken into account when selecting the study. $\mathrm{AMRI}$ is properly described as an image acquisition technique that has come to mean imaging brain activity. fMRI results may depend on, for example, scanner strength, analysis methods, type of task contrast used, patient compliance and cooperation with the tasks, or medications administered at the time of the procedure; neither selection of fMRI tasks nor data processing methods have been universally standardized. ${ }^{1-4}$ Nonetheless, standard practices are beginning to emerge. 5 The IAP language or memory testing is also not standardized; the reviewed studies vary with regard to the procedure used for comparison. IAP may

From the Department of Neurology (J.P.S.), University of Alabama at Birmingham; Department of Neurology (D.G.), Charleston Area Medical Center, WV; Department of Neurology (J.R.B., S.J.S.), Medical College of Wisconsin, Milwaukee; Children's National Medical Center (W.D.G.), George Washington University, Washington, DC; Departments of Neurosurgery and Radiology (A.J.G.), Brigham and Women's Hospital, Boston, MA; Cincinnati Children's Hospital Research Foundation (S.K.H.), OH; Department of Neurosurgery (J.O.), Seattle Children's Hospital, WA; Department of Neurology (D.C.S.), Oregon Health \& Science University, Portland; Department of Neurology (J.A.F.), New York University, New York; and Clinical Epilepsy Section (W.H.T.), National Institute of Neurological Disorders and Stroke, NIH, Bethesda, MD.

Approved by the Guideline Development, Dissemination, and Implementation Subcommittee on February 29, 2016; by the Practice Committee on March 10, 2016; and by the AAN Institute Board of Directors on October 18, 2016.

This guideline was endorsed by the American College of Radiology on September 14, 2016, and by the American Epilepsy Society on December 14, 2016. Go to Neurology.org for full disclosures. Funding information and disclosures deemed relevant by the authors, if any, are provided at the end of the article. 
be inconclusive in a substantial proportion of patients. Data on healthy volunteers are not available. The goal of this practice guideline is to review available evidence and provide practitioners with evidence-based recommendations for the role of $\mathrm{PMRI}$ in epilepsy surgery evaluation and postsurgical outcome prediction. The guideline authors used the AAN diagnostic and prognostic schemes for rating evidence.

This practice guideline seeks to answer the following clinical questions:

1. Is fMRI comparable with the current standard (IAP) for measuring language lateralization?

2. Can fMRI predict postsurgical language outcomes in patients with epilepsy undergoing brain surgery?

3. Is fMRI comparable with the current standard (IAP) for measuring memory lateralization?

4. Can fMRI predict postsurgical verbal memory outcomes in patients with epilepsy undergoing temporal lobectomy?

5. Can fMRI predict postsurgical nonverbal (visuospatial) memory outcomes in patients with epilepsy undergoing temporal lobectomy?

6. Is there sufficient evidence in terms of diagnostic accuracy and outcome prediction for fMRI to replace the IAP (Wada test) in presurgical evaluation for epilepsy surgery?

DESCRIPTION OF THE ANALYTIC PROCESS The Guideline Development, Dissemination, and Implementation Subcommittee appointed an 11-member panel with special expertise in neuroimaging or epilepsy, or both, and with experience in AAN guideline development. The panel followed the methods described in the 2004 AAN process manual $^{6}$ to develop this guideline. The guideline authors included only peer-reviewed studies in humans (see appendix e-3 for complete search strategy).

Two panelists working independently of each other selected $37 / 172$ possibly relevant articles for full data extraction. Studies with $\mathrm{n}<15$ cases, case reports, meta-analyses, and editorials were excluded. Two panelists rated each article according to the AAN diagnostic and prognostic classification of evidence schemes (appendix e-4). One panelist (J.P.S.) arbitrated differences in ratings until reviewer consensus was achieved. The study methodologist (D.G.) reviewed all articles again to confirm adherence to the classification scheme. The guideline panel linked recommendation strength to evidence strength on the basis of the number of Class I, II, and III studies (appendix e-5).

ANALYSIS OF EVIDENCE Is fMRI comparable with the current standard (IAP) for measuring language lateralization? Because Class I and II studies are available, Class III studies are not discussed. The guideline authors performed an individual patient data metaanalysis on the Class I and II studies in order to address this question in patients with medial temporal lobe epilepsy (MTLE). ${ }^{7-10}$ Additional data were identified (6 Class II studies and 12 Class III studies) that did not specify medial vs lateral temporal localization. ${ }^{11-28}$

Temporal lobe epilepsy. One Class I study included 229 patients with epilepsy, 188 of whom had temporal lobe epilepsy (TLE). ${ }^{9}$ There was concordance with IAP in $81 / 91$ (89\%) for the right and $82 / 97$ (85\%) for the left medial temporal foci. Medial and lateral temporal foci were not explicitly separated in the results, but the presence of medial temporal sclerosis did not affect concordance rate. One Class II study showed a concordance of $12 / 14(86 \%)$ in patients with MTLE and in $3 / 3(100 \%)$ in patients with medial temporal tumors. ${ }^{8}$ In the second Class II study (40 patients), when only the data on the reading task were evaluated, the concordance between $\mathrm{PMRI}$ and IAP was 26/31 for all patients and 9/13 when only patients with medial temporal seizure onset were analyzed. ${ }^{7}$ The last Class II study that compared concordance between fMRI and IAP showed excellent agreement in patients with MTLEs (17/17) and seizures related to medial temporal tumors $(4 / 4) .{ }^{10}$

Extratemporal epilepsy. The Class I study previously mentioned showed concordance between fMRI and IAP in $34 / 41(83 \%)$ of the extratemporal cases. ${ }^{9}$ Of the Class II studies, 1 performed in 40 patients with epilepsy showed that in patients with extratemporal epilepsies the concordance was $8 / 11$ for all IAP results and $8 / 10$ if the patient with IAP bilateral language distribution was excluded. ${ }^{7}$ Another Class II study of 26 patients with epilepsy reported $100 \%$ concordance between fMRI and IAP in $5 / 5$ patients with extratemporal lobe epilepsies. ${ }^{18}$

Of the studies conducted in patients with mixed or unspecified location of seizure onset foci, 1 Class II study showed overall $86 \%$ correlation with IAP in 20 patients with epilepsy or brain tumors, or both, for the sentence task and $89 \%$ for the synonym task; individual patient data were not provided. ${ }^{19}$ A Class II study in 51 patients with epilepsy or brain tumors, or both, indicated moderate correlation $(r=0.68$; $p<$ 0.0001 ) between IAP and fMRI, but again, individual data were not provided to aid the combined anal$\mathrm{ysis}^{20}{ }^{20}$ which is similar to the other 2 Class II studies. ${ }^{23,24}$ Finally, the last Class II study performed in 38 patients with epilepsy showed concordance in $1 / 2$ extratemporal cases. ${ }^{10}$

Meta-analysis of the previously discussed studies found the following concordance rates (considering only definitely right or left IAP results): 201/232 (87\%) for medial temporal foci, $7 / 7$ (100\%) for medial temporal lesions, and $48 / 59$ (81\%) for 
extratemporal foci. Data from studies that included patients with mixed or unspecified foci are harder to interpret because some studies did not clearly specify the focus of localization. We classified these metaanalysis data as Class II because they are composed of 2 Class I and 8 Class II studies.

Conclusions. fMRI possibly provides language lateralization information concordant with that of IAP in $87 \%$ of medial temporal cases (Class II meta-analysis of individual patient data) and in $81 \%$ of extratemporal cases (Class II meta-analysis of individual patient data). There are insufficient data for temporal tumors or lateral temporal cases.

Recommendations. fMRI may be considered as an option in lateralizing language functions in place of IAP in patients with MTLE (Level C), temporal epilepsy in general (Level C), or extratemporal epilepsy (Level C), although patients should be carefully advised of the risks and benefits of fMRI vs IAP during discussions of modality choice in each individual case. The evidence is unclear for patients with temporal neocortical epilepsy or temporal tumors (Level U).

Can fMRI predict postsurgical language outcomes in patients with epilepsy undergoing brain surgery? The panel identified 1 Class II study of 44 patients with left or right TLE associated with hippocampal sclero$\operatorname{sis}^{29}$ and 1 Class III study of 56 patients with left or right MTLE (information regarding hippocampal sclerosis was not provided). ${ }^{27}$ In the Class II study, in patients with left TLE, strong left frontal activation predicted greater postresection decline (sensitivity $100 \%$, specificity $33 \%$, positive predictive value $60 \%$ ), and that the postresection performance depended on greater right frontal language activation shift. ${ }^{29}$ The Class III study showed that stronger leftward lateralization in a temporal lobe region of interest (ROI) during a semantic decision task predicted greater postoperative naming decline (sensitivity of $100 \%$, specificity of $73 \%$, positive predictive value $81 \%$; temporal lobe laterality index [LI] correlation to postoperative Boston Naming Test score: $r=$ -0.64; $p<0.001){ }^{27}$ This study also assessed the ability of IAP language lateralization to predict naming outcome in the same patients. Accuracy of the IAP prediction (sensitivity $92 \%$, specificity $45 \%$, positive predictive value $67 \%$ ) was lower than that of fMRI.

Conclusions. fMRI is possibly effective in aiding the prediction of postsurgical language deficits in patients undergoing presurgical evaluation for possible temporal lobectomy (1 Class II study and 1 Class III study).

Recommendation. $\mathrm{AMRI}$ may be considered for predicting postsurgical language outcomes after anterior temporal lobe (ATL) resection for the control of TLE (Level C).
Is fMRI comparable with the current standard (IAP) for measuring memory lateralization? Of 2 Class II studies, 1 study of 67 patients with TLE employed an fMRI contrast between novel visual scenes and meaningless visual patterns to show a significant correlation $(r=$ $0.31 ; p=0.007$ ) between a hippocampal fMRI LI and IAP memory LI. ${ }^{14}$ The second study found no significant correlation $(r=0.152 ; p=0.47)$ between an IAP memory asymmetry measure and medial temporal fMRI LI in 25 patients with TLE. ${ }^{30}$

Of 2 Class III studies, one conducted in 18 patients with TLE used an fMRI paradigm contrasting novel pictures with previously studied pictures to show that LI computed for the medial temporal lobe (MTL) region correlated $(r=0.49 ; p=0.049)$ with the IAP memory LI. ${ }^{31}$ The second Class III study in 30 patients with TLE showed that the number of activated left MTL voxels in patients with left TLE was positively correlated with left IAP memory score (Spearman $r=0.60 ; p<0.01$ ). ${ }^{32}$

Conclusions. In patients with MTLE, there is Class II evidence that fMRI is comparable with IAP in its ability to lateralize memory functions and may be used for this purpose. The conflicting data from one study may be related to a relatively high dose of sodium amobarbital used to perform the IAP.

Recommendation. fMRI may be considered as an option to lateralize memory functions in place of IAP in patients with MTLE (Level C).

Can fMRI predict postsurgical verbal memory outcomes in patients undergoing temporal lobectomy? Nine Class II and 3 Class III studies provided data addressing this question. ${ }^{14,22,30,33-40, \mathrm{el}}$ Class III data are not discussed further. ${ }^{22,38,40}$ In one Class II study of 122 patients with TLE (60 left), 50\% of the variance in postsurgical verbal memory outcome in patients with left TLE was explained by preoperative neuropsychological testing, whereas fMRI explained an additional $10 \%$ of the variance $(p \leq 0.003) .{ }^{33}$ A previously mentioned Class II study found that, in contrast to lateralization of language network activation, lateralization of hippocampal activation during the picture encoding task was not predictive of postresection verbal memory outcomes. ${ }^{14}$ Another Class II study examined asymmetry of hippocampal activation and postsurgical memory outcomes in 54 patients with TLE (29 left), using a word-encoding fMRI paradigm and stepwise linear regression to test associations between fMRI activation and postoperative memory changes after ATL. ${ }^{34}$ The degree of fMRI asymmetry toward the left was correlated with postsurgical verbal memory decline $(p=0.028)$. A model including left fMRI activation during delayed recognition, side of seizure onset, and preoperative verbal memory score correctly predicted worsening of postoperative verbal memory in 
$90 \%$ of patients. ${ }^{30} \mathrm{~A}$ recent Class II study conducted in 50 patients with TLE (23 left) showed that increasing left lateralization in the frontotemporal verbal memory network preresection was associated with postresection verbal memory decline in patients with left TLE $(r=$ 0.44; $p=0.037$ ); this effect was not observed in patients with right TLE. $^{39}$ In additional Class II studies, postsurgical memory outcome was related to presurgical fMRI memory lateralization. ${ }^{36,37}$ Finally, one Class II study showed in 21 patients with left or right TLE that greater functional connectivity between the hippocampus and Brodmann area 22 (superior temporal gyrus) before surgical resection was associated with decreased verbal memory function after surgery. ${ }^{\mathrm{el}}$

Conclusion. fMRI leftward activation asymmetry during encoding of verbal material, regardless of whether measured in the MTL or in the language network, probably predicts verbal memory decline after left MTL surgery (9 Class II studies that used different methods).

Recommendation. Presurgical fMRI of verbal memory or of language encoding should be considered as an option to predict verbal memory outcome in patients with epilepsy who are undergoing evaluation for left MTL surgery (Level B).

Can fMRI predict postsurgical nonverbal (visuospatial) memory outcomes in patients with epilepsy undergoing medial temporal lobectomy? One Class II study (72 patients, 68 with unilateral hippocampal sclerosis) found that asymmetry of face recognition-related activation was the best predictor of visual-spatial decline after surgery (greater right anterior MTLE activation for encoding faces correlates with greater visual memory decline after right ATL resection: $r=$ $0.47 ; p=0.02) .^{34}$

Conclusion. fMRI activation asymmetry during nonverbal (scene and face recognition) memory tasks is possibly predictive of nonverbal memory decline after MTL surgery (1 Class II study).

Recommendation. Presurgical fMRI using nonverbal memory encoding may be considered as a means to predict visuospatial memory outcomes in patients with epilepsy who are undergoing evaluation for temporal lobe surgery (Level C).

Is there sufficient evidence in terms of diagnostic accuracy and outcome prediction for fMRI to replace the IAP (Wada test) in presurgical evaluation for epilepsy surgery? The IAP is used to assess risk to language and memory functions before brain surgery. fMRI has some inherent advantages over the IAP, including lower risk, greater potential for localization of function, and lower cost. Whether fMRI is a suitable replacement for the IAP, however, depends on whether it produces results that are concordant with those from the
IAP and whether it can predict cognitive outcomes as accurately as the IAP.

Language. Several studies address the issue of concordance between fMRI and IAP language lateralization. Concordance is generally high, but not $100 \%$ (table 1). The evidence for the ability of fMRI to predict language outcome (i.e., risk to language function from surgery) is limited to 1 Class II study and 1 Class III study. ${ }^{27,29}$ Data on the ability of IAP to predict language outcome also are limited.

Conclusions. Based on data from 1 Class II study and 1 Class III study, fMRI is possibly an effective method of lateralizing language functions in patients undergoing presurgical evaluation and may be a suitable replacement for the IAP for this purpose. Data on the ability of fMRI to predict language outcomes are limited.

Recommendation. Presurgical fMRI may be used instead of the IAP for language lateralization in patients with epilepsy who are undergoing evaluation for brain surgery (Level C). However, when fMRI is used for this purpose, task design, data analysis methods, and epilepsy type (temporal vs extratemporal, lesional vs nonlesional) need to be considered. Of particular importance for patients with lesional epilepsy is the fact that only small numbers of participants with variable lesion size/location were included in previous studies.

Memory. The objectives of the memory portion of the IAP are to assess risk of global amnesia after ATL resection, even though IAP reliability for this purpose has been questioned, ${ }^{2-e 5}$ and to predict materialspecific verbal memory deficits. ${ }^{\text {e6-e } 9}$

Concordance is modest between IAP memory asymmetry and fMRI MTL activation asymmetry. Because of this low concordance rate and the limited ability of the IAP to predict postoperative verbal memory outcome, a crucial clinical question is whether fMRI can predict memory outcome better than the IAP. In a previously discussed Class II study of 60 patients who had undergone left ATL surgery, an fMRI language LI was more strongly correlated with verbal memory change on a standardized list-learning measure $(r=0.44 ; p<0.001)$ than was the IAP memory asymmetry $(r=0.30 ; p<0.05)$. Moreover, a multivariate prediction model that included preoperative memory score, age at seizure onset, and fMRI LI was not improved by adding IAP asymmetry scores. ${ }^{33}$

Conclusion. The correlations between $\mathrm{AMRI}$ and IAP memory asymmetry measures are modest, and the ability of the memory IAP to predict material-specific verbal memory change is relatively weak. Based on 9 Class II studies, including one study that showed that fMRI of language LI is possibly more accurate in predicting material-specific verbal memory change than was the memory IAP in patients undergoing left ATL resection, fMRI may be an alternative to IAP memory 


\begin{tabular}{|c|c|c|c|c|c|c|}
\hline Class I and II & l-intra & arotid & nobarbital procedure language & eralization comparison s & udies & \\
\hline First author, y & Class & No. & Language task & Baseline & Brain region examined & Concordance, \% \\
\hline Adcock et al., $2003^{11}$ & ॥ & 19 & Silent word generation & Fixation & Language & 100 \\
\hline \multirow[t]{4}{*}{ Arora et al., $2009^{7}$} & ॥ & 37 & Sentence judgment (auditory) & Tone comparison & Hemisphere & 0 \\
\hline & & 38 & Sentence judgment (visual) & Line comparison & & 68 \\
\hline & & 31 & Silent word generation & Line comparison & & 65 \\
\hline & & 28 & All tasks combined & & & 71 \\
\hline \multirow[t]{2}{*}{ Benke et al., $2006^{12}$} & । & 68 & Semantic decision (auditory) & Tone decision & Frontal lobe & 78 \\
\hline & & & & & Temporal & 69 \\
\hline Binder et al., $1996^{13}$ & 1 & 22 & Semantic decision (auditory) & Tone decision & Hemisphere & 100 \\
\hline Chlebus et al., $2007^{15}$ & 1 & 15 & Silent word generation & Rest & Frontal lobe & 100 \\
\hline \multirow[t]{3}{*}{ Deblaere et al., $2004^{16}$} & । & 17 & Silent word generation & Silent counting & Frontal lobe & 100 \\
\hline & & & & & Hemisphere & 94 \\
\hline & & & & & Temporal & 82 \\
\hline Ellmore et al., $2010^{17}$ & ॥ & 23 & Silent naming and word generation & Fixation & Frontal lobe & 91 \\
\hline \multirow[t]{3}{*}{ Gutbrod et al., $2012^{19}$} & ॥ & 20 & Rhyme decision & Letter decision & Frontal $^{\mathrm{a}}$ & $84-88$ \\
\hline & & & Synonym decision & & Temporal $^{\mathrm{a}}$ & $82-84$ \\
\hline & & & Sentence decision & & Combined $^{a}$ & 90 \\
\hline \multirow[t]{3}{*}{ Gaillard et al., $2004^{8}$} & 1 & 25 & Silent word generation & Rest & Language & 84 \\
\hline & & & + Reading comprehension & Passive visual patterns & & \\
\hline & & & + Auditory comprehension & Rest or reversed speech & & \\
\hline Janecek et al., $2013^{9}$ & ॥ & 229 & Semantic decision (auditory) & Tone decision & Language & 86 \\
\hline \multirow[t]{4}{*}{ Rutten et al., $2002^{25}$} & $॥$ & 18 & Silent verb generation only & Shape decision & Language & 72 \\
\hline & & & Silent verb generation & & & \\
\hline & & & + Silent object naming & & & \\
\hline & & & + Silent sentence reading & & Language & 83 \\
\hline Sabbah et al., $2003^{26}$ & ॥ & 20 & Silent word generation & Rest & Hemisphere & 95 \\
\hline \multirow[t]{2}{*}{ Szaflarski et al., $2008^{10}$} & ॥ & 28 & Silent verb generation & Finger tapping & Language & 82 \\
\hline & & 27 & Semantic decision (auditory) & Tone decision & & 78 \\
\hline
\end{tabular}

testing. The ability of fMRI to predict global amnesia has not been assessed.

Recommendation. $\mathrm{fMRI}$ of language and verbal memory lateralization may be an alternative to IAP memory testing for prediction of verbal memory outcome in MTLE (Level C). fMRI is not yet established as an alternative to the IAP for prediction of global amnesia in patients who have undergone ATL surgery.

CLINICAL CONTEXT Several Class I-III studies provide support for fMRI use for language mapping, although several reservations are warranted. Much of the evidence was derived from relatively small patient samples with heterogeneous characteristics. Some studies were underpowered or susceptible to random variation. Few studies have examined the ability of fMRI to predict language outcomes. Multicenter studies are missing, and there are no data about generalizability across centers.
The available evidence leaves many critical matters unresolved. The imperfect concordance between fMRI and IAP language lateralization leaves open the question of which test is more accurate in discordant cases. Although the IAP has been considered a reference standard, it is susceptible to a number of limitations resulting from individual variation in arterial anatomy (i.e., circle of Willis), variable effects of anesthesia, rate of amobarbital or methohexital injection, variation in patient cooperation, and variation in testing methods. Evidence concerning the relative accuracy of IAP and fMRI in predicting language outcomes is limited to a single study. ${ }^{\mathrm{el}}{ }^{0}$ Another important clinical question is the extent to which the published results apply to children and adolescents, patients with varying seizure focus location or lesion types, and patients with different levels of cognitive performance or ability to cooperate with the procedure. The vast majority of the available data are from adults with TLE and minimal structural lesions. A few 
studies suggest less reliable results in patients with extratemporal foci and larger lesions. Several studies included adolescents and children as young as 6 years. Although results appear similar to those in adults, there are no Class I or II studies that solely address fMRI in comparison with IAP or outcomes in the younger age ranges. The reviewed studies varied across a number of methodologic features, including the strength of the magnetic field used, expertise in the techniques used for analysis of the raw data, thresholding method (if any), ROI examined, and lateralization method. The extent to which these variables affect data quality and validity is currently unknown.

The present recommendations assume that published standards are followed for conducting clinical fMRI studies. As with the IAP, cognitive fMRI is a complex diagnostic procedure that requires both advanced technical expertise in imaging and expert interaction with patients to elicit adequate levels of task performance, select a set of activation tasks appropriate to the patient's ability and the clinical aims of the study, instruct the patient on the tasks, administer the tasks during scanning, and evaluate and provide corrective feedback on task performance during the scanning session. ${ }^{\text {e11 }}$ Compliance with the activation tasks is a prerequisite for eliciting the modulation of brain activity on which fMRI depends. Clinicians need to have a thorough understanding of the cognitive processes (language and nonlanguage) elicited by the tasks and be mindful of the advantages and disadvantages of particular language and baseline or contrast tasks.

Ten years ago, practitioners were not ready to address the matter of replacing the memory portion of the IAP with AMRI, and the evidence with regard to memory localization and lateralization with $\mathrm{PMRI}$ is still not as clear or straightforward as with the language tasks. Two Class II studies with relatively large participant samples have now shown that fMRI can predict verbal memory outcome in left ATL surgery $^{33,34}$ and may be more accurate than IAP for this purpose. ${ }^{33}$ Some practitioners, however, depend on the IAP to assess risk for global amnesia, which has been reported after bilateral MTL damage..$^{\text {el2-e14 }}$ Global amnesia is rare after unilateral temporal lobe surgery, however, and occurs mainly when there is preexisting contralateral MTL dysfunction. ${ }^{\text {e2,e5,e15,e16 }}$ One possible approach, therefore, is to reserve use of the IAP memory test for those patients at greatest risk for global amnesia, that is, patients undergoing unilateral ATL resection who have structural or functional evidence of damage to the contralateral MTL.

RECOMMENDATIONS FOR FUTURE RESEARCH

There is a great need for further research in a number of areas, including the following:
- Studies comparing fMRI and IAP with regard to their ability to predict language and memory outcomes

- Studies comparing the ability of fMRI to predict language and memory outcomes in patients receiving various surgical treatments

- Studies comparing various fMRI language and memory tasks in regard to their ability to lateralize functions, their level of agreement with IAP, and their ability to predict postsurgical outcomes

- Studies comparing various fMRI analysis methods, using level of agreement with IAP and ability to predict postsurgical outcomes as standards

- Multicenter studies assessing the replicability of particular fMRI methods across centers

- Studies specifically targeting patients with extratemporal epilepsy and lesional epilepsy

- Studies specifically targeting pediatric epilepsy populations

CONFLICT OF INTEREST The American Academy of Neurology is committed to producing independent, critical, and truthful clinical practice guidelines (CPGs). Significant efforts are made to minimize the potential for conflicts of interest to influence the recommendations of this CPG. To the extent possible, the AAN keeps separate those who have a financial stake in the success or failure of the products appraised in the CPGs and the developers of the guidelines. Conflict of interest forms were obtained from all authors and reviewed by an oversight committee prior to project initiation. AAN limits the participation of authors with substantial conflicts of interest. The AAN forbids commercial participation in, or funding of, guideline projects. Drafts of the guideline have been reviewed by at least 3 AAN committees, a network of neurologists, Neurology peer reviewers, and representatives from related fields. The AAN Guideline Author Conflict of Interest Policy can be viewed at aan. com. For complete information on this process, access the 2004 AAN process manual. ${ }^{6}$

\section{AUTHOR CONTRIBUTIONS}

Dr. Szaflarski: study concept and design, acquisition of data, analysis or interpretation of data, drafting/revising the manuscript, critical revision of the manuscript for important intellectual content, study supervision. Dr. Gloss: acquisition of data, analysis or interpretation of data, drafting/ revising the manuscript, critical revision of the manuscript for important intellectual content, study supervision. Dr. Binder: acquisition of data, analysis or interpretation of data, drafting/revising the manuscript, critical revision of the manuscript for important intellectual content, study supervision. Dr. Gaillard: acquisition of data, analysis or interpretation of data, drafting/ revising the manuscript, critical revision of the manuscript for important intellectual content, study supervision. Dr. Golby: acquisition of data, analysis or interpretation of data, drafting/revising the manuscript, critical revision of the manuscript for important intellectual content, study supervision. Dr. Holland: acquisition of data, analysis or interpretation of data, drafting/ revising the manuscript, critical revision of the manuscript for important intellectual content, study supervision. Dr. Ojemann: acquisition of data, 
analysis or interpretation of data, drafting/revising the manuscript, critical revision of the manuscript for important intellectual content, study supervision. Dr. Spencer: acquisition of data, analysis or interpretation of data, drafting/revising the manuscript, critical revision of the manuscript for important intellectual content, study supervision. Dr. Swanson: acquisition of data, analysis or interpretation of data, drafting/revising the manuscript, critical revision of the manuscript for important intellectual content, study supervision. Dr. French: acquisition of data, analysis or interpretation of data, drafting/revising the manuscript, critical revision of the manuscript for important intellectual content, study supervision. Dr. Theodore: acquisition of data, analysis or interpretation of data, drafting/revising the manuscript, critical revision of the manuscript for important intellectual content, study supervision.

\section{STUDY FUNDING}

This guideline was developed with financial support from the American Academy of Neurology (AAN). Authors who serve as AAN subcommittee members or methodologists (D.G., J.A.F.) were reimbursed by the AAN for expenses related to travel to subcommittee meetings where drafts of manuscripts were reviewed.

\section{DISCLOSURE}

J. Szaflarski has served, in the past 2 years, as a consultant for GW Pharmaceuticals, Inc., Upsher-Smith Laboratories, Inc., Sage Pharmaceuticals, Inc., and Biomedical Systems, Inc.; has served or serves on the editorial boards of Epilepsy \& Behavior, Epilepsy Currents (contributing editor), Journal of Epileptology (associate editor), Journal of Medical Science, Folia Medica Copernicana, Restorative Neurology and Neuroscience (associate editor), and Conference Papers in Medicine; has received funding for research from the US Department of Defense (DOD), US Food and Drug Administration, American Epilepsy Society, SAGE Pharmaceuticals, Inc., Eisai, Inc., UCB Pharmaceuticals, the National Institute of Neurological Disorders and Stroke of the NIH, the State of Alabama ("Carly's Law"), and the University of Alabama at Birmingham; and has served as an expert witness in legal proceedings. D. Gloss is an evidence-based methodologist of the American Academy of Neurology. J. Binder serves on the editorial boards of Brain and Language, Brain Imaging and Behav ior, the Journal of Neuroimaging, Frontiers in Auditory Cognitive Neuroscience, the Journal of Cognitive Neuroscience, and Neuropsychology and receives funding for research from the NIH and the Medical College of Wisconsin. W. Gaillard reports support from Research Triangle International and grant support from the NIH, the Centers for Disease Control and Prevention, the DOD, the National Science Foundation (NSF), Citizens United for Research in Epilepsy, Pediatric Epilepsy Research Foundation, and BAND and serves on the editorial boards for Epilepsia and Epilepsy Research. A. Golby serves on the editorial boards of Brain Imaging and Behavior, the Journal of Neuroimaging, the Journal of Cancer Translational Medicine, and NeuroImage: Clinical; serves as an associate editor of Neurosurgery; and has received research funding from the NIH, Harvard Catalyst, and Koh-Young Technology, Inc. S. Holland reports grant support from 4 entities within the NIH (the National Institute of Neurological Disorders and Stroke, the National Institute of Mental Health, the Eunice Kennedy Shriver National Institute of Child Health and Human Development, and the National Institute on Deafness and Other Communication Disorders) and from the Schiff Family Foundation, the Schroth Family Foundation, the Fischer Family Foundation, and PNC Bank Foundation. J. Ojemann is a board member of Therma Neuroscience, Inc.; receives funding from the NIH and the NSF; is a member of the Epilepsy Foundation Northwest professional advisory board; and serves on the editorial boards of Neurosurgery and the Journal of Neurosurgery. D. Spencer has served as an editor for Neurology ${ }^{\circledR}$ and the Neurology patient page; has received research support from NeuroPace, Inc.; and has given a deposition in a legal proceeding. S. Swanson has received support from the Epilepsy Foundation of America and the NIH and has served as an expert witness in civil and criminal legal proceedings. J. French receives New York University (NYU) salary support for consulting work on behalf of the Epilepsy Study Consortium for Acorda, Adamas, Alexza, Anavex, BioPharm Solutions, Cerecor, Concert Pharmaceuticals, Eisai, Georgia Regents University, GW Pharmaceuticals, Marinus, Monteris Medical, Nestlé Health Science, Neurelis, Novartis,
Pfizer, Pfizer Neusentis Research and Development, Pronutria, Roivant Sciences, Sage Therapeutics, SciFluor Life Sciences, SK Life Science, Sunovion, Takeda, UCB, Inc., Upsher-Smith, Xenon Pharmaceuticals, Zogenix, and Zynerba; has received personal compensation for serving as associate editor of Epilepsia; received research grants from the commercial entities Acorda, Alexza, Eisai Medical Research, Lewis County General Hospital, Lundbeck, Pfizer, SK Life Science, Sunovion, UCB, UpsherSmith, and Vertex; has received grants from the noncommercial entities Epilepsy Research Foundation, Epilepsy Study Consortium, Epilepsy Therapy Project, and the National Institute of Neurological Disorders and Stroke of the NIH; serves on the editorial boards of Lancet Neurology, Neurology Today, and Epileptic Disorders; is scientific officer for the Epilepsy Foundation of America, for which NYU receives salary support; and has received travel reimbursement related to research, advisory meetings, or presentation of results at scientific meetings from the Epilepsy Study Consortium, the Epilepsy Foundation of America, Eisai, GW Pharmaceuticals, Marinus, Nestlé Life Sciences, Pfizer, Sage, SK Life Science, Takeda, UCB, Upsher-Smith, Zogenix, and Zynerba. W. Theodore is an employee of the National Institute of Neurological Disorders and Stroke of the NIH, which provides salary, travel, and research support; has served as co-editor-in-chief for Epilepsy Research, and on editorial boards for Lancet Neurology, Neurology, Epilepsia, Acta Neurologica Scandinavica, and Neurotherapeutics; and has received support from the International League Against Epilepsy for teaching in Zambia. Go to Neurology.org for full disclosures.

\section{DISCLAIMER}

Clinical practice guidelines, practice advisories, systematic reviews, and other guidance published by the American Academy of Neurology and its affiliates are assessments of current scientific and clinical information provided as an educational service. The information (1) should not be considered inclusive of all proper treatments, methods of care, or as a statement of the standard of care; (2) is not continually updated and may not reflect the most recent evidence (new evidence may emerge between the time information is developed and when it is published or read); (3) addresses only the question(s) specifically identified; (4) does not mandate any particular course of medical care; and (5) is not intended to substitute for the independent professional judgment of the treating provider, as the information does not account for individual variation among patients. In all cases, the selected course of action should be considered by the treating provider in the context of treating the individual patient. Use of the information is voluntary. AAN provides this information on an "as is" basis, and makes no warranty, expressed or implied, regarding the information. AAN specifically disclaims any warranties of merchantability or fitness for a particular use or purpose. AAN assumes no responsibility for any injury or damage to persons or property arising out of or related to any use of this information or for any errors or omissions.

Received April 26, 2016. Accepted in final form September 9, 2016.

\section{REFERENCES}

1. Loring DW, Meador KJ, Allison JD, et al. Now you see it, now you don't: statistical and methodological considerations in fMRI. Epilepsy Behav 2002;3: 539-547.

2. Szaflarki JP, Allendorfer JB. Topiramate and its effect on fMRI of language in patients with right or left temporal lobe epilepsy. Epilepsy Behav 2012;24:74-80.

3. Vannest JJ, Karunanayaka PR, Altaye M, et al. Comparison of fMRI data from passive listening and activeresponse story processing tasks in children. J Magn Reson Imaging 2009;29:971-976.

4. Yasuda CL, Centeno M, Vollmar C, et al. The effect of topiramate on cognitive fMRI. Epilepsy Res 2013;105: 250-255.

5. Best Practices in Data Analysis and Sharing in Neuroimaging Using MRI. Minneapolis: The Organization for Human Brain Mapping (OHBM) Web site. Available at: humanbrainmapping.org/files/2016/COBIDAS-Final\%20For \%20Vote.pdf. Accessed June 15, 2016. 
6. American Academy of Neurology. Clinical Practice Guidelines Process Manual, 2004 ed. St. Paul: The American Academy of Neurology; 2004. Available at: aan.com/Guidelines/ Home/UnderDevelopment. Accessed November 12, 2009.

7. Arora J, Pugh K, Westerveld M, Spencer S, Spencer DD, Todd Constable R. Language lateralization in epilepsy patients: fMRI validated with the Wada procedure. Epilepsia 2009;50:2225-2241.

8. Gaillard WD, Balsamo L, Xu B, et al. fMRI language task panel improves determination of language dominance. Neurology 2004;63:1403-1408.

9. Janecek JK, Swanson SJ, Sabsevitz DS, et al. Language lateralization by $\mathrm{fMRI}$ and Wada testing in 229 patients with epilepsy: rates and predictors of discordance. Epilepsia 2013;54:314-322.

10. Szaflarski JP, Holland SK, Jacola LM, Lindsell C, Privitera MD, Szaflarski M. Comprehensive presurgical functional MRI language evaluation in adult patients with epilepsy. Epilepsy Behav 2008;12:74-83.

11. Adcock JE, Wise RG, Oxbury JM, Oxbury SM, Matthews PM. Quantitative fMRI assessment of the differences in lateralization of language-related brain activation in patients with temporal lobe epilepsy. Neuroimage 2003;18: 423-438.

12. Benke T, Koylu B, Visani P, et al. Language lateralization in temporal lobe epilepsy: a comparison between $\mathrm{AMRI}$ and the Wada Test. Epilepsia 2006;47:1308-1319.

13. Binder JR, Swanson SJ, Hammeke TA, et al. Determination of language dominance using functional MRI: a comparison with the Wada test. Neurology 1996;46:978-984.

14. Binder JR, Swanson SJ, Sabsevitz DS, Hammeke TA, Raghavan M, Mueller WM. A comparison of two fMRI methods for predicting verbal memory decline after left temporal lobectomy: language lateralization versus hippocampal activation asymmetry. Epilepsia 2010;51:618-626.

15. Chlebus P, Mikl M, Brazdil M, Pazourkova M, Krupa P, Rektor I. fMRI evaluation of hemispheric language dominance using various methods of laterality index calculation. Exp Brain Res 2007;179:365-374.

16. Deblaere K, Boon PA, Vandemaele P, et al. MRI language dominance assessment in epilepsy patients at $1.0 \mathrm{~T}$ : region of interest analysis and comparison with intracarotid amytal testing. Neuroradiology 2004;46:413-420.

17. Ellmore TM, Beauchamp MS, Breier JI, et al. Temporal lobe white matter asymmetry and language laterality in epilepsy patients. Neuroimage 2010;49:2033-2044.

18. Gaillard WD, Balsamo L, Xu B, et al. Language dominance in partial epilepsy patients identified with an fMRI reading task. Neurology 2002;59:256-265.

19. Gutbrod K, Spring D, Degonda N, et al. Determination of language dominance: Wada test and fMRI compared using a novel sentence task. J Neuroimaging 2012;22:266-274.

20. Jones SE, Mahmoud SY, Phillips MD. A practical clinical method to quantify language lateralization in fMRI using whole-brain analysis. Neuroimage 2011;54:2937-2949.

21. Kamada K, Sawamura Y, Takeuchi F, et al. Expressive and receptive language areas determined by a non-invasive reliable method using functional magnetic resonance imaging and magnetoencephalography. Neurosurgery 2007;60: 296-305; discussion 305-306.

22. Koylu B, Walser G, Ischebeck A, Ortler M, Benke T. Functional imaging of semantic memory predicts postoperative episodic memory functions in chronic temporal lobe epilepsy. Brain Res 2008;1223:73-81.
23. Ota T, Kamada K, Kawai K, Yumoto M, Aoki S, Saito N. Refined analysis of complex language representations by non-invasive neuroimaging techniques. $\mathrm{Br} \mathrm{J}$ Neurosurg 2011;25:197-202.

24. Rodin D, Bar-Yosef O, Smith ML, Kerr E, Morris D, Donner EJ. Language dominance in children with epilepsy: concordance of fMRI with intracarotid amytal testing and cortical stimulation. Epilepsy Behav 2013;29:7-12.

25. Rutten GJ, Ramsey NF, van Rijen PC, Alpherts WC, van Veelen CW. fMRI-determined language lateralization in patients with unilateral or mixed language dominance according to the Wada test. Neuroimage 2002;17:447-460.

26. Sabbah P, Chassoux F, Leveque C, et al. Functional MR imaging in assessment of language dominance in epileptic patients. Neuroimage 2003;18:460-467.

27. Sabsevitz DS, Swanson SJ, Hammeke TA, et al. Use of preoperative functional neuroimaging to predict language deficits from epilepsy surgery. Neurology 2003;60:1788-1792.

28. Woermann FG, Jokeit H, Luerding R, et al. Language lateralization by Wada test and fMRI in 100 patients with epilepsy. Neurology 2003;61:699-701.

29. Bonelli SB, Thompson PJ, Yogarajah M, et al. Imaging language networks before and after anterior temporal lobe resection: results of a longitudinal fMRI study. Epilepsia 2012;53:639-650.

30. Dupont S, Duron E, Samson S, et al. Functional MR imaging or Wada test: which is the better predictor of individual postoperative memory outcome? Radiology 2010;255:128-134.

31. Deblaere K, Backes WH, Tieleman A, et al. Lateralized anterior mesiotemporal lobe activation: semirandom functional MR imaging encoding paradigm in patients with temporal lobe epilepsy: initial experience. Radiology 2005;236:996-1003.

32. Jokeit H, Okujava M, Woermann FG. Memory fMRI lateralizes temporal lobe epilepsy. Neurology 2001;57:1786-1793.

33. Binder JR, Sabsevitz DS, Swanson SJ, Hammeke TA, Raghavan M, Mueller WM. Use of preoperative functional MRI to predict verbal memory decline after temporal lobe epilepsy surgery. Epilepsia 2008;49:1377-1394.

34. Bonelli SB, Powell RH, Yogarajah M, et al. Imaging memory in temporal lobe epilepsy: predicting the effects of temporal lobe resection. Brain 2010;133:1186-1199.

35. Bonelli SB, Thompson PJ, Yogarajah M, et al. Memory reorganization following anterior temporal lobe resection: a longitudinal functional MRI study. Brain 2013;136:1889-1900.

36. Cheung MC, Chan AS, Lam JM, Chan YL. Pre- and postoperative $\mathrm{AMRI}$ and clinical memory performance in temporal lobe epilepsy. J Neurol Neurosurg Psychiatry 2009;80:1099-1106.

37. Frings L, Wagner K, Halsband U, Schwarzwald R, Zentner J, Schulze-Bonhage A. Lateralization of hippocampal activation differs between left and right temporal lobe epilepsy patients and correlates with postsurgical verbal learning decrement. Epilepsy Res 2008;78:161-170.

38. Mechanic-Hamilton D, Korczykowski M, Yushkevich PA, et al. Hippocampal volumetry and functional MRI of memory in temporal lobe epilepsy. Epilepsy Behav 2009;16:128-138.

39. Sidhu MK, Stretton J, Winston GP, et al. Memory fMRI predicts verbal memory decline after anterior temporal lobe resection. Neurology 2015;84:1512-1519.

40. Vannest J, Szaflarski JP, Privitera MD, Schefft BK, Holland SK. Medial temporal fMRI activation reflects memory lateralization and memory performance in patients with epilepsy. Epilepsy Behav 2008;12:410-418. 


\section{Neurology}

Practice guideline summary: Use of fMRI in the presurgical evaluation of patients with epilepsy: Report of the Guideline Development, Dissemination, and Implementation Subcommittee of the American Academy of Neurology

Jerzy P. Szaflarski, David Gloss, Jeffrey R. Binder, et al. Neurology 2017;88;395-402 Published Online before print January 11, 2017

DOI 10.1212/WNL.0000000000003532

\section{This information is current as of January 11, 2017}

\section{Updated Information \& Services}

Supplementary Material

\section{References}

\section{Citations}

Subspecialty Collections

Permissions \& Licensing

Reprints including high resolution figures, can be found at: http://n.neurology.org/content/88/4/395.full

Supplementary material can be found at: http://n.neurology.org/content/suppl/2017/01/11/WNL.0000000000003 532.DC1

This article cites 38 articles, 7 of which you can access for free at: http://n.neurology.org/content/88/4/395.full\#ref-list-1

This article has been cited by 10 HighWire-hosted articles: http://n.neurology.org/content/88/4/395.full\#\#otherarticles

This article, along with others on similar topics, appears in the following collection(s):

All Epilepsy/Seizures

http://n.neurology.org/cgi/collection/all_epilepsy_seizures

fMRI

http://n.neurology.org/cgi/collection/fmri

Functional neuroimaging

http://n.neurology.org/cgi/collection/functional_neuroimaging

Information about reproducing this article in parts (figures,tables) or in its entirety can be found online at:

http://www.neurology.org/about/about_the_journal\#permissions

Information about ordering reprints can be found online:

http://n.neurology.org/subscribers/advertise

Neurology ${ }^{\circledR}$ is the official journal of the American Academy of Neurology. Published continuously since 1951, it is now a weekly with 48 issues per year. Copyright () 2017 American Academy of Neurology. All rights reserved. Print ISSN: 0028-3878. Online ISSN: 1526-632X.

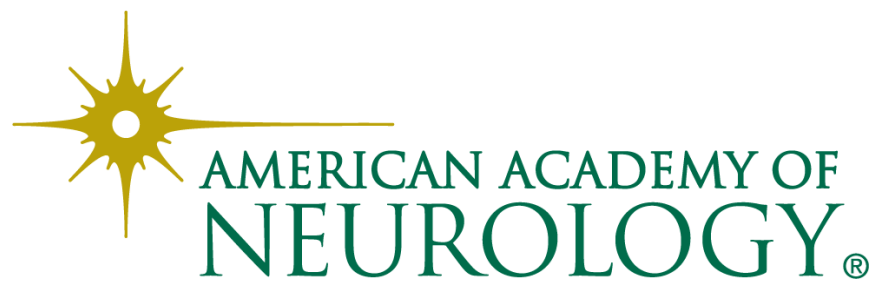

